\title{
A RELAÇÃO ENTRE INTENSIDADE TECNOLÓGICA E GRAU DE INTANGIBILIDADE NO DESEMPENHO ECONÔMICO-FINANCEIRO DA INDÚSTRIA BRASILEIRA
}

\author{
THE RELATIONSHIP BETWEEN TECHNOLOGICAL INTENSITY AND INTANGIBILITY DEGREE IN \\ FINANCIAL PERFORMANCE OF BRAZILIAN INDUSTRY
}

\section{Guilherme Afrânio Machado}

Graduado em Administração pela Faculdade de Gestão e Negócios da Universidade Federal de Uberlândia, Uberlândia (MG), Brasil

\section{Luciana Carvalho}

Professora do Programa de Pós-Graduação em Administração da Faculdade de Gestão e Negócios da Universidade Federal de Uberlândia, Uberlândia (MG), Brasil

\section{Fernanda Maciel Peixoto}

Professora do Programa de Pós-Graduação em Administração da Faculdade de Gestão e Negócios da Universidade Federal de Uberlândia, Uberlândia (MG), Brasil
Data de recebimento: 04-07-2016

Data de aceite: 06-06-2017

\section{RESUMO}

Este trabalho buscou verificar a influência da intensidade tecnológica na relação entre o grau de intangibilidade e o desempenho econômico-financeiro na indústria brasileira. Para tanto, valeu-se da classificação da Organização para Cooperação e Desenvolvimento Econômico (OCDE). A amostra envolveu empresas brasileiras listadas na BM\&FBovespa de 2011 a 2015. A técnica estatística contou com dados em painel com efeitos fixos e aleatórios conforme teste Hausman. No que concerne às variáveis, para traduzir a dimensão intangível das organizações o grau de intangibilidade foi utilizado como variável dependente, enquanto retorno sobre ativos (ROA), retorno sobre o Patrimônio Líquido (ROE) e retorno, medidos pela diferença do preço das ações ao longo do ano, foram empregados como variáveis independentes representando o desempenho econômico-financeiro. Os resultados revelaram que não existe diferença significativa quanto à relação intangibilidade-desempenho entre setores com alta e média-alta intensidade tecnológica e baixa e média-baixa intensidade tecnológica. Ademais, observou-se que o grau de intangibilidade não exerceu influência significativa em indicadores, como ROA, ROE e retorno, para a amostra e o período investigados.

Palavras-chave: Grau de intangibilidade; desempenho econômico-financeiro; intensidade tecnológica.

\section{ABSTRACT}

This study aimed to verify the influence of technological intensity in the relationship between the intangibility degree and economic-financial performance in the Brazilian industry. Therefore, we used the classification of Organization for Economic Cooperation and Development (OECD). The sample involved Brazilian companies listed on the BM\&FBovespa from 2011 to 2015. The statistical technique relied on panel data with fixed and random effects, as Hausman test. Regarding the variables, to translate the intangible dimension of organizations, intangibility degree was used as the dependent variable, while return on assets (ROA), return on equity (ROE) and return were used as independent variables representing economic-financial performance. The results revealed that there is no significant difference in the intangibility-performance ratio among sectors with high and medium-high technological intensity and low and medium-low technology. Furthermore, it was observed that the Intangibility degree does not exert significant influence on indicators such as ROA, ROE, and Return for the sample and period investigated.

Keywords: Intangibility degree; economic-financial performance; technological intensity. 


\section{INTRODUÇÃO}

Diversos trabalhos têm discutido o impacto da produção do conhecimento no desempenho das empresas (AHANGAR, 2011; BONTIS; KEOW; RICHARDSON, 2000; CABRITA; BONTIS, 2008; CARVALHO; KAYO; MARTIN, 2010; CHEN; CHENG; HWANG, 2005; KAMATH, 2008; LAURETTI, 2011; MAZZIONI et al., 2014; NASCIMENTO et al., 2012; RIAHI-BELKAOUI, 2003; PEREZ; FAMÁ, 2006; PULIĆ, 2008; TAN; PLOWMAN; HANCOCK, 2007). O cenário econômico mundial vem se transformando rapidamente e se torna cada vez mais evidente a transição da era industrial para a era do conhecimento. A principal diferença entre tais contextos reside no fato de que antes a criação de valor pelas corporações dependia da quantidade de trabalho executado, enquanto na era do conhecimento o valor é determinado pelo saber incorporado em bens ou serviços (PULIĆ, 2008).

A desmaterialização das atividades econômicas atribuiu destaque para a produção de conhecimento na construção de novas fontes de ofertas de valor para as empresas, de modo que o capital financeiro e o trabalho, aspectos tradicionalmente valorizados, não são mais suficientes para criar vantagens competitivas sustentáveis (DRUCKER, 1988). Ativos como marcas, patentes, conhecimento organizacional, softwares e outros ganharam relevância estratégica. Com efeito, a capacidade dos trabaIhadores em transformar e incorporar seus conhecimentos em valor identificável no mercado passou a ser chamada de capital intelectual ou ativo intangível (MAZZIONI et al., 2014; PULIĆ, 2008).

A complexidade na identificação, definição e mensuração do ativo intangível forma hoje um dos campos mais complexos e desafiadores da contabilidade, como também das finanças corporativas (HENDRIKSEN; VAN BREDA, 1999; PEREZ; FAMÁ, 2006). Lev (2001) demonstra a importância da mensuração em pesquisa realizada com empresas estadunidenses, na qual aponta que a proporção entre o valor de mercado e o valor patrimonial saltou de um para seis de 1977 a 2001. Isso significa que o mercado atribui às empresas um valor consideravelmente maior que seu valor patrimonial como consequência de uma avaliação que vai além dos aspectos tangíveis das corporações. Tais resultados evidenciam a grande dificuldade da contabilidade tradicional em registrar os ativos intangíveis e seus componentes nos demonstrativos contábeis das organizações (PEREZ; FAMÁ, 2006). Nesse contexto, a utilização isolada dos tradicionais índices financeiros para análise do desempenho das empresas como indicadores de sucesso começou a sofrer críticas, pois não leva em conta o aspecto intangível, ou seja, não diz se o valor foi criado ou quanto foi criado (PULIĆ, 2008), implicando em uma análise incompleta do desempenho das organizações.

No caso do Brasil, ainda não existe um consenso no que se refere ao impacto dos intangíveis no desempenho das empresas. Ahangar (2011), Lauretti (2011) e Mazzioni et al. (2014) encontraram resultados positivos na relação entre desempenho econômico e intangibilidade. No entanto, Carvalho, Kayo e Martin (2010) e Nascimento et al. (2012) não encontraram evidências da relação positiva entre desempenho econômico-financeiro e intangibilidade.

Diante do exposto, este artigo objetiva responder ao seguinte problema de pesquisa: Existe relação entre o desempenho econômico-financeiro e a grandeza da intangibilidade das organizações? Assim, o objetivo geral desta pesquisa consiste em investigar empiricamente qual a relação entre a dimensão intangível de empresas brasileiras e seus indicadores de desempenho financeiro tradicionais. Por sua vez, o objetivo específico consiste em compreender se há alguma diferença nessa relação ao analisar empresas de alta e baixa intensidade tecnológica.

Este trabalho pretende contribuir para a literatura empírica acerca da relação entre desempenho 
econômico-financeiro e intangibilidade em dois aspectos principais: (1) realiza um estudo comparativo entre empresas de alta e baixa intensidade tecnológica; (2) utiliza o método de regressão com dados em painel ainda pouco explorado para os estudos de intangibilidade.

A pesquisa se justifica ao contribuir para o entendimento da relação entre intangibilidade e desempenho em cenário nacional, dada a baixa quantidade de estudos sobre esse tema voltados para empresas brasileiras. Além disso, a estratificação da amostra em empresas de alta e baixa intensidade tecnológica traz uma nova perspectiva e permite entender se empresas de características similares manifestam alguma particularidade nessa possível relação.

Adiante, apresenta-se uma revisão da literatura com os principais conceitos empregados para o desenvolvimento deste trabalho. Posteriormente, serão expostos os aspectos metodológicos, seguidos de análise dos dados e considerações finais.

\section{REFERENCIAL TEÓRICO}

\subsection{Definição e reconhecimento do ativo intangível}

Definir precisamente os ativos intangíveis é uma tarefa bastante complexa (CARVALHO; KAYO; MARTIN, 2010). Vários enfoques foram dados no meio acadêmico e, hoje, os ativos intangíveis já são conhecidos por diversas outras nomenclaturas, como capital intelectual (CHEN; CHENG; HWANG, 2005), ativos do conhecimento (DENICOLAl; ZUCCHELLA; STRANGE, 2014), ativos invisíveis (SVEIBY, 1998) e goodwill (MONOBE, 1986). Tal dificuldade de definição, acompanhada de incertezas quanto à mensuração de valores e vida útil dos ativos intangíveis, transforma-os em um dos objetos de estudo mais complexos da teoria da contabilidade (HENDRIKSEN; VAN BREDA, 1999). Apesar do crescente interesse dos pesquisadores, não há consenso acerca de uma definição, ou sequer uma tendência nesse sentido (MAZZIONI et al., 2014).

O entendimento dos ativos intangíveis, como simplesmente aqueles que não têm existência física ou não podem ser tocados, é simplório e incorreto (PEREZ; FAMÁ, 2006). Ativos não corpóreos, como depósitos bancários, contas a receber e títulos de investimento, são considerados tangíveis (MONOBE, 1986). Além disso, ativos intangíveis devem apresentar respaldo tangível, isto é, devem estar registrados ou revelar evidência física de sua existência (REILLY; SCHWEIHS, 1998). Assim, apenas as características relacionadas à existência física não são suficientes para diferenciar ativos tangíveis de intangíveis (HENDRIKSEN, 1965).

Chang e Hsieh (2011) entendem os ativos intangíveis como capital intelectual. Para os autores, o capital intelectual não é um ativo estático, mas um processo ideológico de movimentação constante entre "possuir conhecimento e habilidades" e "utilizar conhecimento e habilidades". O capital intelectual pode ser entendido ainda como o material intelectual (conhecimento, experiência, informação) que pode ser convertido em valor à organização (STEWART, 1997). Tal perspectiva se associa à visão de ativos do conhecimento. Também são intangíveis os ativos codificados e reportados em documentos das organizações, seja por patentes, direitos autorais, modelos de design, licenças, softwares inovativos e outros custos capitalizados para o desenvolvimento de novos conhecimentos (DENICOLAl; ZUCCHELLA; STRANGE, 2014).

Enquanto a perspectiva econômica de ativos é mais abrangente, a perspectiva contábil acerca do tema é mais restrita (CARVALHO; KAYO; MARTIN, 2010). No Brasil, o Comitê de Pronunciamentos Contábeis (CPC), por meio do Pronunciamento técnico CPC 04 (R1), define ativo intangível como um ativo não monetário, identificável e sem substância física quando: (1) é separável da entidade, estando apto a ser vendido, transferido, licenciado, 
alugado ou trocado, independentemente da intenção de uso pela entidade; ou (2) resulta em direitos contratuais ou outros direitos legais (COMITÊ DE PRONUNCIAMENTOS CONTÁBEIS, 2010).

Somente a existência de um ativo não é o bastante para que ele seja reconhecido contabilmente. Para tanto, é necessário que: (1) os benefícios econômicos futuros atribuíveis ao ativo sejam gerados em favor da entidade; (2) o custo do ativo possa ser mensurado de maneira confiável (COMITÊ DE PRONUNCIAMENTOS CONTÁBEIS, 2010).

Caso um ativo intangível não atenda aos critérios, ele não pode ser reconhecido contabilmente. Nota-se, portanto, bastante dificuldade de reconhecimento de ativos intangíveis criados ou desenvolvidos dentro das organizações devido à subjetividade envolvida em seu entendimento (PEREZ; FAMÁ, 2006).

\subsection{Estrutura e classificação do capital intelectual}

Avançando no entendimento do capital intelectual, Bontis (1998) conclui que este é composto por três dimensões inter-relacionadas: capital humano, capital estrutural e capital relacional (Quadro 1).

Quadro 1 - Estrutura do capital intelectual: principais aspectos

\begin{tabular}{|c|c|c|c|}
\cline { 2 - 4 } \multicolumn{1}{c|}{} & \multicolumn{3}{c|}{ Capital intelectual } \\
\cline { 2 - 4 } & $\begin{array}{c}\text { Capital } \\
\text { humano }\end{array}$ & $\begin{array}{c}\text { Capital } \\
\text { estrutural }\end{array}$ & $\begin{array}{c}\text { Capital } \\
\text { relacional }\end{array}$ \\
\hline Essência & $\begin{array}{c}\text { Intelecto } \\
\text { humano }\end{array}$ & $\begin{array}{c}\text { Processos } \\
\text { organizacionais }\end{array}$ & $\begin{array}{c}\text { Relacionamento } \\
\text { de mercado }\end{array}$ \\
\hline Escopo & $\begin{array}{c}\text { Relacionado } \\
\text { com o } \\
\text { empregado }\end{array}$ & $\begin{array}{c}\text { Ligações } \\
\text { organizacionais } \\
\text { internas }\end{array}$ & $\begin{array}{c}\text { Ligações } \\
\text { organizacionais } \\
\text { externas }\end{array}$ \\
\hline
\end{tabular}

Fonte: Bontis (1998).

O capital humano tem como essência o intelecto humano e, portanto, é fortemente relacionado ao corpo de empregados da corporação, sendo constituído por suas competências, seu comprometimento, sua motivação, sua educação, seus valores, entre outros (CABRITA; BONTIS, 2008; CHEN; CHENG; HWANG, 2005; EDVINSON; MALONE, 1997). Apesar de o capital humano ser considerado o coração do capital intelectual e a fonte para a inovação, por ser dependente dos empregados pode desaparecer com a saída destes (BONTIS, 1998; STEWART, 1999). Por esse motivo, é importante que o conhecimento seja compartiIhado e transferido entre os membros da organização, em busca de maximizar o valor da empresa por meio da inter-relação entre todos os intangíveis (KAYO, 2002).

Nesse contexto, o capital estrutural se torna fundamental, pois, como apontam Cabrita e Bontis (2008), é essa dimensão do capital intelectual que provê as ferramentas e estruturas para guardar e manter o conhecimento em movimento por toda a cadeia de valor. Contrastando-se ao capital humano, o capital estrutural, por sua vez, pertence à organização, não sendo constituído por ativos humanos, mas por sistemas de informação, processos e bases de dados (CABRITA; BONTIS, 2008; CHEN; CHENG; HWANG, 2005).

O capital relacional, por sua vez, é representado pelo conhecimento incorporado no relacionamento com clientes, fornecedores, associações do setor ou qualquer outro stakeholder que exerça influência na organização (CABRITA; BONTIS, 2008).

Em classificação proposta por Kayo (2002), ativos intangíveis são determinados com base em suas características na intenção de uniformizar os termos. Tal classificação expõe forte associação com a estrutura do capital intelectual e facilita seu entendimento. No Quadro 2, apresentam-se as classificações do intangível e seus principais componentes.

De acordo com a classificação, os ativos humanos e de inovação são inerentes ao capital humano, da mesma forma como os ativos estruturais e ativos relacionais correspondem ao entendimento de capital estrutural e capital relacional, respectivamente. 
Quadro 2 - Classificação de ativos intangíveis

\begin{tabular}{|c|c|}
\hline Tipo de intangível & Principais componentes \\
\hline Ativos humanos & $\begin{array}{c}\text { Conhecimento, talento, capacidade, } \\
\text { habilidade e experiência dos } \\
\text { empregados; Administração superior } \\
\text { ou empregados-chave; treinamento e } \\
\text { desenvolvimento. }\end{array}$ \\
\hline Ativos de inovação & $\begin{array}{c}\text { Pesquisa e desenvolvimento; } \\
\text { patentes; fórmulas secretas; know- } \\
\text { how tecnológico. }\end{array}$ \\
\hline Ativos estruturais & $\begin{array}{c}\text { Processos; softwares proprietários; } \\
\text { bancos de dados; sistemas de } \\
\text { informação; sistemas administrativos; } \\
\text { inteligência de mercado; canais de } \\
\text { mercado. }\end{array}$ \\
\hline Ativos de & $\begin{array}{c}\text { Marcas; logos; trademarks; direitos } \\
\text { autorais; contratos com clientes, } \\
\text { fornecedores, entre outros; contratos } \\
\text { de licenciamento, franquias, entre } \\
\text { outros; direitos de exploração } \\
\text { mineral, de água, entre outros. }\end{array}$ \\
\hline
\end{tabular}

Fonte: Kayo (2002).

\subsection{Mensuração do capital intelectual}

A medição dos ativos intangíveis é uma área de pesquisa relativamente recente (SABOLOVIC, 2009). Não obstante o crescente reconhecimento do capital intelectual como direcionador do valor das empresas e suas vantagens competitivas, suas formas de mensuração ainda são controversas, sendo que cada pesquisador o calcula à sua maneira (CHEN; CHENG; HWANG, 2005; PULIĆ, 2008).

No geral, as abordagens de mensuração de intangíveis se enquadram nas quatro seguintes categorias, as quais são uma extensão das classificações sugeridas por Sveiby (2010), também aceitas por Ahangar (2011):

a) Métodos de capital intelectual direto: estimam o valor monetário de ativos intangíveis ao identificar seus vários componentes. Uma vez que tais componentes são identificados, podem ser avaliados diretamente, seja individualmente ou como um coeficiente agregado. b) Métodos de capitalização de mercado: calculam a diferença entre o valor de mercado das empresas e seu valor contábil como valor do capital intelectual ou de seus ativos intangíveis.

c) Métodos de retorno sobre ativos (ROA): o ROA de uma empresa é comparado com a média do seu setor de atuação. A diferença é multiplicada pela média de ativos tangíveis da empresa para calcular uma média anual de ganhos a partir dos intangíveis. A divisão do lucro acima da média, pelo custo de capital médio ou de uma taxa de juros, resulta em uma estimativa do valor dos ativos intangíveis ou capital intelectual.

d) Métodos do Scorecard (SC): os vários componentes do capital intelectual ou ativos intangíveis são identificados de modo que indicadores e índices são gerados e reportados em quadros de desempenho ou gráficos.

Em levantamento realizado por Sveiby (2010), foram encontradas 57 formas de mensuração dos ativos intangíveis que englobam as quatro abordagens supracitadas, compreendendo métodos desde a década de 1950 até 2009.

O primeiro método listado no levantamento de Sveiby (2010) é o do Q de Tobin, o qual representa, conforme Famá e Barros (2000), a razão entre o valor de mercado da empresa e o custo de reposição de seus ativos físicos. Em finanças, o Q de Tobin pode ser utilizado: (1) como indicador de oportunidades de novos investimentos; (2) como proxy para o valor da corporação, expressando o valor da empresa em sentido de desempenho, facilitando a comparação entre empresas; e (3) no geral, como variável dependente na busca de relações de causalidade entre o valor da firma e outras variáveis (FAMÁ; BARROS, 2000). O Q de Tobin pode ser categorizado como um método de mensuração de intangíveis de capitalização de mercado, visto que envolve o valor de mercado em seu cálculo. 
Outro método de avaliação de intangíveis que vem se popularizando atualmente é o método VAIC TM (do inglês, value added intellectual coefficient). Traduzido livremente como "coeficiente do valor adicionado pelo capital intelectual", foi desenvolvido em 1998 por Ante Pulić, com intuito de medir e gerenciar a eficiência do valor adicionado pela habilidade intelectual das corporações em uma economia baseada no conhecimento (CHEN; CHENG; HWANG, 2005; PULIĆ, 1998; YU et al., 2011). Empresas com alto VAIC ${ }^{\mathrm{TM}}$ conseguem criar mais valor com os recursos disponíveis. Tal coeficiente permite aos gestores mensurar o capital intelectual com base em informações contábeis e compará-lo ao de competidores em seus respectivos setores (CHANG; HSIEH, 2011). Para tanto, o método mede a eficiência em três pilares: (1) capital físico e financeiro; (2) capital humano; e (3) capital estrutural. O VAIC TM é um método de mensuração baseado no ROA.

Outra maneira de mensuração bastante popular na academia é o grau de intangibilidade (Gl ou book-to-market), o qual representa a razão do valor de mercado de uma empresa pelo seu valor contábil. Quanto maior o índice, maior a participação relativa de ativos intangíveis na estrutura da empresa (KAYO, 2002). Também é um método de mensuração com base na capitalização de mercado e tem uma grande vantagem por ser intuitivo e de cálculo simples.

\subsection{Ativos intangíveis e desempenho empresarial}

Os recursos e competências acumuladas são, de acordo com a resource based view (RBV, em português, visão baseada em recursos), as principais causas na variação de desempenho das organizações (CARVALHO; KAYO; MARTIN, 2010). As empresas constroem vantagem competitiva e alcançam desempenho superior por meio de aquisição, posse e uso de recursos estratégicos, tangíveis ou intangíveis (RIAHI-BELKAOUI, 2003; WERNERFELT, 1984).
Apesar de o termo vantagem competitiva ser amplamente disseminado nas diversas áreas da economia e administração em geral, ainda não há consenso em sua definição. Contudo, entende-se que uma empresa detém vantagem competitiva quando apresenta desempenho financeiro acima do normal perante os competidores do setor e de forma sustentável (BARNEY, 2010; BESANKO et al., 2011; CRUZ; FREITAS; SHARLAND, 2009; PETERAF, 1993). Isso somente pode ser alcançado por meio da utilização de recursos estratégicos (RIAHIBELKAOUI, 2003).

Barney (1991) caracteriza um recurso como estratégico quando este atende a quatro condições: (1) possui valor; (2) é raro ou escasso; (3) é difícil de imitar; (4) é difícil de substituir. Enquanto o acesso à aquisição de ativos tangíveis pelas organizações é relativamente simples, a posse de intangíveis se torna fator de diferenciação, visto que, devido a suas características, geralmente não são comercializáveis e precisam ser desenvolvidos continua e internamente nas empresas (RIAHI-BELKAOUI, 2003). Os ativos intangíveis reúnem a habilidade de possuírem todas as características de um ativo estratégico (GODFREY; HILL, 1995), apesar de nem sempre serem qualificados como tal (MOURITSEN, 1988). Ainda que possuam importância destacada na criação de vantagem competitiva, Perez e Famá (2006) fazem ressalva ao afirmar que o valor da empresa somente é definido mediante a interação das duas naturezas de ativos, não sendo uma menos importante que a outra, por isso a relevância da gestão estratégica de ativos.

\subsection{Evidências empíricas da relação intangibilidade-desempenho}

Diversos estudos empíricos buscaram encontrar evidências para compreender e contextualizar a relação entre intangibilidade e desempenho (AHANGAR, 2011; CABRITA; BONTIS, 2008; CARVALHO; KAYO; MARTIN, 2010; CHAGAS et al., 
2010; CHEN; CHENG; HWANG, 2005). Mazzioni et al. (2014) realizaram um estudo que buscou identificar a relação entre o Gl e o desempenho econômico das empresas de capital aberto e dos diversos setores dos países que compõem os Brics (Brasil, Rússia, Índia, China e África do Sul). Os autores utilizaram modelos econométricos com dados em painel com efeitos fixos e aleatórios. As variáveis usadas para representar o desempenho financeiro foram ROA, giro do ativo e retorno sobre patrimônio líquido (ROE), enquanto o GI representou a dimensão intangível das empresas pesquisadas. Os resultados indicaram diversas relações estatisticamente significativas quanto à influência do GI das empresas dos Brics no desempenho econômico. Os autores chegaram à conclusão de que a presença de intangíveis contribui positivamente para o desempenho das organizações.

Em pesquisa realizada em uma empresa iraniana, Ahangar (2011) valeu-se de técnicas de regressão linear múltipla para avaliar a relação entre os componentes do capital intelectual e seu desempenho financeiro. Para tanto, aplicou o método VAIC TM para identificar o desempenho do valor adicionado pelo capital intelectual, enquanto rentabilidade, produtividade dos empregados e crescimento de vendas foram as variáveis escolhidas para traduzir o desempenho da organização. $\mathrm{O}$ autor concluiu que o desempenho do capital intelectual, em especial do capital humano, pode explicar rentabilidade e produtividade.

Com resultados bastante semelhantes aos de Chen, Cheng e Huang (2005) em empresas taiwanesas, e igualmente com o objetivo de investigar a relação entre capital intelectual e desempenho financeiro das empresas, Tan, Plowman e Hancock (2007) também recorreram ao método VAICTM como forma de avaliação do intangível de empresas da Singapore Exchange (SGX). Os resultados demonstraram que: (1) o capital intelectual e o desempenho empresarial estão positivamente relacionados; (2) o capital intelectual está correlacionado ao desempenho futuro das companhias; e (3) a contribuição do capital intelectual para o desempenho das companhias varia conforme o setor.

Entre as poucas pesquisas realizadas com empresas brasileiras, Lauretti (2011) traz resultados interessantes, dentre os quais: (1) valida o GI como proxy para a intangibilidade por meio de teste de correlação com o Q de Tobin; (2) encontra forte relação positiva entre intangibilidade e desempenho financeiro sustentável; e (3) constata que a intangibilidade e o desempenho financeiro estão positivamente correlacionados quando este é mensurado pelo ROA.

Já a pesquisa de Carvalho, Kayo e Martin (2010), também centrada em empresas brasileiras, buscou avaliar a relação da intangibilidade ou tangibilidade dos recursos com o desempenho sustentável das firmas. Os autores se valeram de técnicas de painel dinâmico com estimativas pelo método dos momentos generalizados e, diferentemente de outras pesquisas, os resultados demonstraram que a intangibilidade não afetou positivamente o desempenho financeiro, sendo os recursos tangíveis fontes mais relevantes de vantagem competitiva sustentável.

Visando contextualizar a importância dos ativos intangíveis no mundo, pode-se citar como exemplos os estudos de Axtle-Ortiz (2013), Rezaie e Salehi (2015), Arrighetti, Landini e Lasagni (2014) e Elbannan (2013).

Axtle-Ortiz (2013) estudou o valor dos ativos intangíveis em um extenso trabalho que envolveu oito regiões geográficas, dezesseis setores da indústria, dois tipos de operações e três tamanhos de organização. A pesquisa demonstrou que a região geográfica, o setor industrial e o tamanho da firma são fatores estatisticamente significativos que influenciam o valor dos ativos intangíveis. Em suma, Axtle-Ortiz (2013) identificou os principais componentes que moldam o capital intelectual e o modo como é caracterizado. 
Axtle-Ortiz (2013) ressaltou ainda que a única maneira possível de gerenciar ativos intangíveis é estar ciente de sua composição e reconhecer seu valor na organização. Destacou também que diferentes organizações em diferentes contextos valorizam os componentes do capital intelectual de formas distintas. Só é possível comparar organizações dentro de contextos semelhantes e em indústrias similares. O que é importante para uma organização em uma determinada indústria não é necessariamente relevante para outra organização em um setor diferente. A localização é outro fator que afeta a avaliação de componentes do capital intelectual, pois os resultados podem variar de acordo com a região.

Sob ótica distinta, Elbannan (2013) buscou investigar se os analistas de economias emergentes têm preferência por estudar organizações que possuam maior volume de ativos intangíveis de 1999 a 2007. Em seu estudo, o autor supõe que quanto maior o volume de ativos intangíveis das empresas, mais analistas estarão interessados em buscar informações privadas sobre essas companhias. O autor utiliza diversos proxies para ativos intangíveis, dentre eles: despesas com pesquisa e desenvolvimento (P\&D) divididas pelo total de despesas operacionais; despesas de publicidade divididas pelo total de despesas operacionais; ativos intangíveis registrados divididos pelo ativo total; despesas de depreciação divididas pelo total de despesas operacionais; medidas similares ponderadas pelo setor de atividades da firma. Como resultados, Elbannan (2013) constatou que a cobertura dos analistas está associada a despesas de $P \& D$, despesas de publicidade, tamanho da empresa e volume de negócios.

Nessa mesma linha de estudos, Rezaie e Salehi (2015), em estudo com o objetivo investigar os efeitos da heterogeneidade sobre ativos intangíveis das empresas listadas na bolsa de valores do Irã, verificaram que não há diferença significativa entre o montante de investimento em ativos intangíveis entre empresas em relação ao seu tamanho. Além disso, não há diferença significativa entre o investimento em ativos intangíveis em empresas com e sem restrições de financiamento. A população desta pesquisa incluiu todas as empresas listadas na bolsa de valores d e Teerã (161 empresas) de 2003 a 2012. A metodologia estatística aplicada foi a de regressão linear multivariada e de análise de variância.

Arrighetti, Landini e Lasagni (2014) investigaram os fatores determinantes que aumentam a probabilidade de empresas italianas investirem em ativos intangíveis em2008. Para tanto, os autores utilizaram modelos de regressão probit para testar as seguintes hipóteses: (1) firmas de maior tamanho têm maior probabilidade de investir em ativos intangíveis; (2) firmas com mais capital humano têm maior probabilidade de investir em ativos intangíveis; (3) firmas com maior complexidade organizacional têm maior probabilidade de investir em ativos intangíveis; (4) firmas que historicamente são mais intensivas em ativos intangíveis (têm maior volume de ativos intangíveis no passado) têm maior probabilidade de investir neles.

Arrighetti, Landini e Lasagni (2014) utilizaram um rico quadro de variáveis, por exemplo, para mensurar o capital humano, adotaram uma combinação de duas variáveis distintas. A primeira foi um índice sintético elaborado com uma análise fatorial que utilizou como inputs a relação entre funcionários "colarinhos brancos" e "colarinhos azuis"; o número de anos de educação do funcionário e a percentagem de trabalhadores titulares de diploma universitário. Por sua vez, a segunda variável de capital humano mediu a porcentagem de funcionários envolvidos em P\&D. Para mensurar a complexidade organizacional, os autores utilizaram variáveis que mensuraram o nível de internacionalização da firma, a subcontratação de serviços e o turnover dos funcionários, entre outros mecanismos. 
Como resultados principais, Arrighetti, Landini e Lasagni (2014) verificaram que o tamanho da firma, o capital humano e o nível anterior de intensidade de capital intangível aumentaram significativamente a probabilidade de a firma investir em ativos intangíveis. Com relação ao proxy da complexidade organizacional, pelo contrário, a evidência foi mais fraca. Esses resultados foram obtidos após o controle de setores relacionados à indústria.

\section{METODOLOGIA}

Dado que o objetivo deste trabalho consistiu em avaliar a relação entre desempenho econômico-financeiro e Gl de empresas brasileiras listadas na BM\&FBovespa, foram definidos os aspectos metodológicos destacados adiante.

\subsection{Técnica estatística}

A metodologia proposta neste artigo emprega a análise de dados em painel para os anos 2012, 2013 e 2014 . Esta investigação destina-se a examinar como o Gl das indústrias brasileiras influencia em seu desempenho econômico-financeiro.

Os modelos de dados em painel diferem dos modelos com dados temporais e cortes transversais, dado o caráter duplo que atribui a cada variável:

$$
Y \_i t=a+b X \_1 i t+b X \_2 i t+u \_i t
$$

Nota: i: $1, \ldots, \mathrm{n}$ : indivíduos ( $\mathrm{n}$ indivíduos, países, regiões, empresas, setores); t: 1,..., T: períodos de tempo (T períodos).

Se para cada indivíduo "i" se dispõe do mesmo número de dados temporais, o painel é denominado de balanceado (ou equilibrado). Em outras palavras, um painel é balanceado quando cada unidade de corte transversal tem o mesmo número de observações. Se o número de dados temporais não é o mesmo para todos os indivíduos, o painel se denomina desbalanceado (GUJARATI; PORTER,
2011; WOOLDRIDGE, 2010). Neste trabalho, os painéis utilizados foram não balanceados.

Nos modelos que utilizam efeitos fixos, a estimação é feita assumindo-se que a heterogeneidade dos indivíduos se capta na parte constante, que é diferente de indivíduo para indivíduo, captando diferenças invariantes no tempo (por exemplo, dimensão dos países, recursos naturais e outras características que não variam em curto prazo). Nos modelos com "efeitos aleatórios", a estimação é feita introduzindo a heterogeneidade dos indivíduos no termo de erro (WOOLDRIDGE, 2010).

O teste Hausman foi empregado para decidir qual dos modelos seria apropriado: o modelo de efeitos aleatórios $\left(\mathrm{H}_{0}\right)$ ou o modelo de efeitos fixos $\left(\mathrm{H}_{\mathrm{A}}\right)$. O teste se apresenta da seguinte forma:

$$
\begin{aligned}
& H_{-} 0=\operatorname{Cov}(\text { a_i,X_it })=0 \text { (efeitos aleatórios) } \\
& H_{-} \mathrm{A}=\operatorname{Cov}\left(a_{-} \text {i,X_it }\right) \neq 0 \text { (efeitos fixos) }
\end{aligned}
$$

Sob a hipótese nula, os estimadores do modelo com efeitos aleatórios são consistentes e eficientes. Sob a hipótese alternativa, os estimadores de mínimos quadrados generalizados (GLS) com efeitos aleatórios (mínimos quadrados ordinários - OLS) são não consistentes, mas os estimadores com efeitos fixos são consistentes. Esta é uma das vantagens dos modelos com efeitos fixos, uma vez que permitem a endogeneidade dos regressores.

Dessa forma, a equação genérica dos modelos a serem estimados pode ser descrita por:

Desempenho econômico $=\alpha+\lambda_{1}(\mathrm{Gl})+\lambda_{2}$ (liquidez corrente) $+\lambda_{3}$ (índice de eficiência o peracional) $+\lambda_{4}$ (participação do capital de terceiros) + $\lambda_{5}($ InAtivo $)+u_{i t}$

\subsection{Composição e seleção da amostra}

Para a realização desta pesquisa, foram selecionadas todas as empresas listadas na BM\&FBovespa. Para a delimitação da amostra, 
foram mantidas somente empresas de atividade industrial. Restaram, portanto, 198 empresas, dos mais diversos setores da economia, com observações dos anos 2012, 2013 e 2014. Todos os dados necessários para as análises foram extraídos da base de dados Economática. Destaca-se que o recorte do período de 2012 a 2014 ocorreu devido à qualidade dos dados diante da adequação às normas internacionais de contabilidade.

A amostra foi classificada em dois grupos: (1) empresas de alta a média-alta intensidade tecnológica e (2) empresas de baixa a média-baixa intensidade tecnológica. Para tanto, com base na categorização de setores da Economática, seguiu-se a classificação proposta pela Organização para a Cooperação e Desenvolvimento Econômico (OCDE), que divide os setores em quatro grupos principais de intensidade tecnológica:

a) Alta intensidade tecnológica: setor aeroespacial; farmacêutico; de informática; eletrônica e telecomunicações; instrumentos;

b) Média-alta intensidade tecnológica: setores de material elétrico; veículos automotores; químico (exceto farmacêutico); ferroviário; de equipamentos de transporte; máquinas e equipamentos;

c) Média-baixa intensidade tecnológica: setores de construção naval; borracha e produtos plásticos; coque, produtos refinados de petróleo e de combustíveis nucleares; outros produtos não metálicos; metalurgia básica e produtos metálicos;

d) Baixa intensidade tecnológica: outros setores e reciclagem; madeira, papel e celulose; editorial e gráfico; alimentos, bebidas e fumo; têxtil e de confecção, couro e calçados.

Com intuito de simplificar a análise, as quatro categorias supracitadas foram agrupadas em duas: alta e média-alta intensidade tecnológica e média e média-baixa intensidade tecnológica.

\subsection{Seleção das variáveis}

Com o objetivo de responder ao problema desta pesquisa, foram selecionadas variáveis que representassem a intangibilidade e o desempenho econômico-financeiro das companhias. Foram consideradas as variáveis mais utilizadas pela academia nos estudos da relação entre intangibilidade e desempenho (AHANGAR, 2011; CHAGAS et al., 2010; CHANG; HSIEH, 2011; KAMATH, 2008).

As variáveis selecionadas como dependentes para indicar o desempenho econômico das empresas são apresentadas no Quadro 3, enquanto as variáveis explicativas do desempenho econômico das empresas são expostas no Quadro 4.

Quadro 3 - Variáveis dependentes da pesquisa

\begin{tabular}{|c|c|c|c|c|}
\hline $\begin{array}{c}\text { Grupo de } \\
\text { Indicadores }\end{array}$ & Indicadores & Fórmula de cálculo & Interpretação & Referência \\
\hline \multirow{3}{*}{$\begin{array}{l}\text { Indicadores de } \\
\text { Rentabilidade }\end{array}$} & $\begin{array}{c}\text { Retorno sobre o } \\
\text { Ativo }\end{array}$ & $\mathrm{ROA}=\frac{\mathrm{LL}}{\mathrm{AT}}$ & $\begin{array}{c}\text { Mede a capacidade da empresa } \\
\text { em gerar lucros, considerando os } \\
\text { ativos disponíveis. }\end{array}$ & $\begin{array}{c}\text { Chagas et al. (2010), Chang e } \\
\text { Hsieh (2011), Ahangar (2011), } \\
\text { Kamath (2008). }\end{array}$ \\
\hline & $\begin{array}{l}\text { Retorno sobre o } \\
\text { Patrimônio Líquido }\end{array}$ & $\mathrm{ROE}=\frac{\mathrm{LL}}{\mathrm{PL}}$ & $\begin{array}{c}\text { Informa o retorno que a empresa } \\
\text { conseguiu em relação ao capital } \\
\text { nela investido. }\end{array}$ & $\begin{array}{l}\text { Antunes e Martins (2007), } \\
\text { Chang e Hsieh (2011). }\end{array}$ \\
\hline & Retorno & $\begin{array}{c}\text { Diferença entre o valor } \\
\text { da ação em t com o valor } \\
\text { da ação em t-1 }\end{array}$ & $\begin{array}{l}\text { Ganho no valor de mercado da } \\
\text { empresa. }\end{array}$ & \\
\hline
\end{tabular}

Nota: AT: ativo total; PL: patrimônio líquido; LL: lucro líquido

Fonte: Elaboração dos autores (2015). 
Quadro 4 - Variáveis independentes da pesquisa

\begin{tabular}{|c|c|c|c|c|}
\hline $\begin{array}{c}\text { Grupo de } \\
\text { indicadores }\end{array}$ & Indicadores & Fórmula de cálculo & Interpretação & Referência \\
\hline $\begin{array}{c}\text { Indicadores de } \\
\text { liquidez }\end{array}$ & Liquidez corrente & $\mathrm{LC}=\frac{\mathrm{AC}}{\mathrm{PC}}$ & $\begin{array}{c}\text { Mensura a capacidade da } \\
\text { empresa em honrar seus } \\
\text { compromissos de curto prazo. }\end{array}$ & Trombetta (2010). \\
\hline $\begin{array}{c}\text { Indicadores de } \\
\text { endividamento }\end{array}$ & Leverage & Leverage $=\frac{\mathrm{PC}+\mathrm{PELP}}{\mathrm{AT}}$ & $\begin{array}{c}\text { Indica o grau de "dependência" } \\
\text { da empresa perante seus } \\
\text { credores. }\end{array}$ & $\begin{array}{c}\text { Antunes e Martins } \\
(2007) .\end{array}$ \\
\hline $\begin{array}{c}\text { Grandeza da } \\
\text { intangibilidade }\end{array}$ & $\begin{array}{c}\text { Grau de } \\
\text { intangibilidade }\end{array}$ & $\mathrm{Gl}=\frac{\mathrm{VMA}}{\mathrm{PL}}$ & $\begin{array}{c}\text { Representa a razão do valor de } \\
\text { mercado de uma empresa pelo } \\
\text { seu valor contábil. Quanto maior } \\
\text { o índice, maior a participação } \\
\text { relativa de ativos intangíveis na } \\
\text { estrutura da empresa. }\end{array}$ & $\begin{array}{c}\text { Lev (2001), Kayo (2002), } \\
\text { Cheng e Hwang } \\
(2005), \text { Kamath (2008). }\end{array}$ \\
\hline $\begin{array}{c}\text { Indicadores de } \\
\text { eficiência }\end{array}$ & $\begin{array}{c}\text { Índice de eficiência } \\
\text { operacional }\end{array}$ & $\mathrm{IEO}=\frac{\mathrm{FCO}}{\mathrm{LL}}$ & $\begin{array}{c}\text { Empregado como proxy para } \\
\text { avaliar a produtividade dos } \\
\text { empregados. }\end{array}$ & Bomfim et al. (2011). \\
\hline Tamanho & Size & InAtivo & $\begin{array}{c}\text { Representa o tamanho da } \\
\text { empresa. }\end{array}$ & $\begin{array}{c}\text { Kayo (2002), Chen, } \\
\text { Cheng e Hwang (2005). }\end{array}$ \\
\hline
\end{tabular}

Nota: AC: ativo circulante; AT: ativo total; FCO: fluxo de caixa operacional; LL: lucro líquido; PELP: passivo exigível a longo prazo; PC: passivo circulante; PL: patrimônio líquido; PT: passivo total.

Fonte: Elaboração dos autores (2015).

\section{RESULTADOS E DISCUSSÃO}

\subsection{Análise descritiva}

A amostra foi composta por 172 empresas de 2011 a 2015, totalizando 808 observações-ano.
Destas, 519 observações-ano se referem às empresas de alta e média-alta intensidade tecnológica, enquanto 289 observações restantes se concentram nas indústrias de baixa e média-baixa intensidade tecnológica. A Tabela 1 exibe a análise descritiva da amostra de acordo com a intensidade tecnológica.

Tabela 1 - Visão geral dos principais indicadores das empresas por intensidade tecnológica

\begin{tabular}{|c|c|c|c|c|c|c|}
\hline \multirow{2}{*}{ Variáveis } & \multicolumn{2}{|c|}{$\begin{array}{l}\text { Amostra completa } \\
\qquad(\mathrm{N}=808)\end{array}$} & \multicolumn{2}{|c|}{$\begin{array}{l}\text { Empresas de alta e média-alta } \\
\qquad(\mathrm{N}=519)\end{array}$} & \multicolumn{2}{|c|}{$\begin{array}{l}\text { Empresas de baixa e média-baixa } \\
\qquad(\mathrm{N}=289)\end{array}$} \\
\hline & Média & DP & Média & DP & Média & DP \\
\hline ROE & 127,394 & $2.024,35$ & 149,045 & 2466,902 & 86,518 & 593,449 \\
\hline GI & 2,155 & 6,963 & 2,102 & 6,859 & 2,251 & 7,155 \\
\hline $\mathrm{LC}$ & 2,158 & 3,343 & 2,281 & 4,024 & 1,937 & 1,451 \\
\hline Leverage & 51,701 & 313,504 & 33,317 & 32,141 & 84,714 & 521,384 \\
\hline IEO & 4,765 & 17,841 & 4,765 & 19,482 & 4,767 & 14,399 \\
\hline
\end{tabular}

Fonte: Elaboração dos autores (2015). 
Nota-se que a média do ROA nas indústrias com baixa e média-baixa intensidade tecnológica é consideravelmente menor que nas indústrias de maior intensidade tecnológica, o que aponta maior capacidade destas em prover lucros a partir dos ativos disponíveis.

O ROE acompanha o comportamento do ROA e também é maior nas empresas de alta e média-alta intensidade. Tal diferença pode ser consequência da capacidade de tais companhias em traduzir altos investimentos em P\&D em oportunidades comercializáveis. Isso implica dizer que as empresas com menor intensidade tecnológica revelam condições mais propícias para oferecerem maior retorno sobre o investimento dos acionistas.

Em relação à variável retorno, que representa a diferença nos preços das ações, os resultados revelam melhor desempenho para empresas de média e baixa intensidade tecnológica. Ainda nesse cenário, é interessante observar que empresas com baixa intensidade tecnológica têm grau de intangibilidade maior quando comparadas a empresas de alta intensidade, ainda que apresentem maior variabilidade.

\subsection{Análise de correlações}

A Tabela 2 registra o resultado da análise de correlação entre as variáveis sob investigação. Tal análise demonstra que há baixa, porém significativa, correlação positiva entre ROA e GI. As variáveis que mais influenciam positivamente o retorno sobre ativos são: IEO e ROE. Cabe notar, inclusive, que a participação de capital de terceiros apresenta correlação bastante significativa e negativa em relação ao ROA, ou seja, quanto maior o endividamento, menor a capacidade da indústria de gerar lucros.

De maneira semelhante, o ROE evidencia a correlação significativa e positiva com o Gl, porém negativa em relação à participação com capital de terceiros. Os resultados sugerem que quanto maior a dimensão intangível da companhia, a tendência é que o ROE também seja maior; afirmativa inversa à participação do capital de terceiros, visto que o ROE diminui à medida que a participação cresce.

Tabela 2 - Correlação entre as variáveis da amostra

\begin{tabular}{|c|c|c|c|c|c|c|c|c|}
\hline & ROA & ROE & Retorno & GI & LC & Leverage & IEO & InAtivo \\
\hline ROA & 1,000 & & & & & & & \\
\hline ROE & $0,977 * * *$ & 1,000 & & & & & & \\
\hline Retorno & 0,056 & 0,055 & 1,000 & & & & & \\
\hline GI & $0,610^{*}$ & $0,255 * * *$ & $0,114 * * *$ & 1,000 & & & & \\
\hline LC & $-0,037$ & $-0,032$ & $-0,096 * *$ & $-0,018$ & 1,000 & & & \\
\hline Leverage & $0,125 * * *$ & $-0,046$ & $-0,002$ & $-0,021$ & $-0,057$ & 1,000 & & \\
\hline IEO & $-0,021$ & $-0,015$ & $-0,058$ & $-0,025$ & $-0,034$ & $-0,013$ & 1,000 & \\
\hline InAtivo & $-0,131 * * *$ & $-0,091 * *$ & $-0,255 * * *$ & $-0,041$ & $-0,114 * *$ & $-0,168 * * *$ & 0,051 & 1,000 \\
\hline
\end{tabular}

Nota: ${ }^{*}$ ) Estatisticamente significante ao nível de 10\%; (**) Estatisticamente significante ao nível de 5\% (***); Estatisticamente significante ao nível de $1 \%$. Fonte: Elaboração dos autores (2015).

Portanto, pode-se inferir que o Grau de Intangibilidade apresenta correlação positiva e média com o ROA, afetando positivamente e com mais intensidade o retorno sobre o patrimônio. Em outras palavras, quanto maior a dimensão intangível das empresas, mais positivo será o impacto no retorno sobre os investimentos dos acionistas. O retorno sobre ativos também tenderá a ser melhor, de forma moderada, quanto maior o Grau de Intangibilidade. 
Vale destacar a importância representada pela eficiência operacional quanto ao desempenho das empresas, impactando positiva e significativamente tanto o ROA quanto o ROE.

\subsection{Dados em painel}

Após avaliar os dados sem distinção temporal, seguiu-se uma análise de dados em painel, visando avaliar se o desempenho das indústrias (ROA, ROE, retorno) consegue ser explicado pelo seu Grau de Intangibilidade e outras variáveis explicativas. Para tanto, os dados foram submetidos a testes de normalidade, homocedasticidade, multicolinearidade e ao teste Hausman, para avaliar qual tipo de painel deveria ser utilizado - com efeitos fixos ou aleatórios. Os resultados estão indicados nas Tabelas 3, 4 e 5.

Tabela 3 - Relação entre ROA e o grau de intangibilidade por intensidade tecnológica

\begin{tabular}{|c|c|c|c|}
\hline $\begin{array}{c}\text { Variáveis } \\
\text { Explicativas }\end{array}$ & $\begin{array}{l}\text { Amostra } \\
\text { completa }\end{array}$ & $\begin{array}{c}\text { Alta e } \\
\text { média-alta }\end{array}$ & $\begin{array}{c}\text { Baixa e } \\
\text { média-baixa }\end{array}$ \\
\hline Gl & $\begin{array}{l}-0,073 \\
(0,088) \\
\end{array}$ & $\begin{array}{l}-0,172 \\
(0,116) \\
\end{array}$ & $\begin{array}{c}0,092 \\
(0,129) \\
\end{array}$ \\
\hline LC & $\begin{array}{c}-1,951 * * * \\
(0,292) \\
\end{array}$ & $\begin{array}{c}-1,963 * * * \\
(0,300)\end{array}$ & $\begin{array}{c}0,085 \\
(1,497) \\
\end{array}$ \\
\hline Leverage & $\begin{array}{c}-0,041 * * * \\
(0,004) \\
\end{array}$ & $\begin{array}{c}0,123 * * * \\
(0,043) \\
\end{array}$ & $\begin{array}{c}-9,347 * * * \\
(3,236) \\
\end{array}$ \\
\hline IEO & $\begin{array}{l}-0,036 \\
(0,032) \\
\end{array}$ & $\begin{array}{l}-0,027 \\
(0,037) \\
\end{array}$ & $\begin{array}{l}-0,090 \\
(0,064) \\
\end{array}$ \\
\hline Size & $\begin{array}{c}14,019 * * * \\
(2,021) \\
\end{array}$ & $\begin{array}{c}14,065 * * * \\
(2,587)\end{array}$ & $\begin{array}{c}9,347 * * * \\
(3,236)\end{array}$ \\
\hline Observações & 795 & 514 & 281 \\
\hline $\begin{array}{c}\text { Número de } \\
\text { grupos }\end{array}$ & 171 & 112 & 59 \\
\hline Rho & 0,812 & 0,496 & 0,858 \\
\hline Teste Hausman & $159,92 * * *$ & $37,200 * \star *$ & $137,57 * * *$ \\
\hline Efeitos fixos & SIM & SIM & SIM \\
\hline $\begin{array}{c}\text { Teste Breusch } \\
\text { and Pagan }\end{array}$ & $72,52 * * *$ & $88,67 * * *$ & $3,24 * *$ \\
\hline
\end{tabular}

Nota: *estatisticamente significante ao nível de 10\%; ** estatisticamente significante ao nível de $5 \%$; ${ }^{* *}$ estatisticamente significante ao nível de $1 \%$. Observação: o teste de normalidade não rejeitou a hipótese nula de uma distribuição normal; o hettes (teste de homocedasticidade) não indicou a presença de heterocedasticidade; o teste VIF apresentou coeficiente menor que 10 para todas as variáveis e, assim, não foi identificada multicolinearidade.

Fonte: Elaboração dos autores (2015).
Avaliando-se o ROA como variável dependente (Tabela 3), nota-se que o Gl não apresenta significância explicativa para nenhum dos grupos avaliados, ou seja, o valor do market-to-book (representado pelo GI) não exerce influência sobre o ROA. Esses resultados são semelhantes aos de Fietz e Scarpin (2008), Nascimento et al. (2012) e Kreuzberg, Rigo e Klann (2013), que também não encontraram significância no modelo ao analisar o ROA e a intangibilidade dos ativos das empresas de capital aberto brasileiras.

A variável Leverage, por sua vez, exprime significância negativa para ambos os modelos, o que sugere que o endividamento dessas indústrias tem uma relação negativa com o desempenho econômico. Por sua vez, o IEO não apresentou significância significativa para os modelos estimados. Quanto ao proxy de tamanho, InAtivo, os coeficientes exibiram sinal positivo e significativo nas empresas de baixa e média-baixa intensidade tecnológica somente.

No que se refere ao ROE como variável dependente (Tabela 4), o Gl manifestou significância explicativa e positiva para todos os modelos. Este resultado corrobora Mazzioni et al. (2014) que, em pesquisa para empresas de países que compõem o Brics, encontraram relações positivas e estatisticamente significativas para o ROE. Esses resultados indicam que quanto maior o Gl, maior será o ROE, comprovando parcialmente a hipótese inicial deste estudo.

Quanto à variável Leverage, os resultados são distintos em relação aos modelos estimados com a variável dependente ROA. O coeficiente associado foi significativo e positivo, revelando que o endividamento tem impacto positivo com o ROE. Ademais, o IEO se destaca, apresentando um coeficiente associado positivo e significativo para todos os modelos explicativos do ROE. Quanto maior o IEO, maior será o ROE, de acordo com os dados analisados. Por fim, o tamanho da empresa (size) revelou um coeficiente associado negativo e significativo para os três modelos estimados. 
Tabela 4 - Relação entre ROE e Gl por intensidade tecnológica

\begin{tabular}{|c|c|c|c|}
\hline $\begin{array}{c}\text { Variáveis } \\
\text { explicativas }\end{array}$ & $\begin{array}{l}\text { Amostra } \\
\text { completa }\end{array}$ & $\begin{array}{c}\text { Alta e } \\
\text { média-alta }\end{array}$ & $\begin{array}{c}\text { Baixa e } \\
\text { média-baixa }\end{array}$ \\
\hline Gl & $\begin{array}{c}5,666^{\star * *} \\
(1,228) \\
\end{array}$ & $\begin{array}{c}7,563 * * * \\
(1,568)\end{array}$ & $\begin{array}{c}4,604 * * * \\
(1,226)\end{array}$ \\
\hline LC & $\begin{array}{l}-0,955 \\
(0,615) \\
\end{array}$ & $\begin{array}{l}-1,032 \\
(0,640)\end{array}$ & $\begin{array}{l}-1,559 \\
(1,799)\end{array}$ \\
\hline Leverage & $\begin{array}{c}0,747 * \star \star \\
(0,182)\end{array}$ & $\begin{array}{c}0,939 * * * \\
(0,241)\end{array}$ & $\begin{array}{c}0,438^{* * *} \\
(0,146)\end{array}$ \\
\hline IEO & $\begin{array}{c}0,147 * * \\
(0,603)\end{array}$ & $\begin{array}{l}0,126 * \\
(0,070)\end{array}$ & $\begin{array}{c}0,296 * * * \\
(0,112) \\
\end{array}$ \\
\hline InAtivo & $\begin{array}{c}-13,919 * * * \\
(4,935)\end{array}$ & $\begin{array}{c}-15,145 * * * \\
(5,718)\end{array}$ & $\begin{array}{c}-2,966 * * \\
(1,403) \\
\end{array}$ \\
\hline Observações & 710 & 467 & 448 \\
\hline $\begin{array}{c}\text { Número de } \\
\text { Grupos }\end{array}$ & 160 & 104 & 150 \\
\hline Rho & 0,309 & 0,296 & 0,684 \\
\hline $\begin{array}{c}\text { Teste } \\
\text { Hausman }\end{array}$ & $19,24 * * *$ & $23,97 * * *$ & $3,49 *$ \\
\hline Efeitos Fixos & SIM & SIM & SIM \\
\hline $\begin{array}{c}\text { Teste Breusch } \\
\text { and Pagan }\end{array}$ & $23,22 * * *$ & $11,70 * * *$ & $10,13 * * *$ \\
\hline
\end{tabular}

Nota: *estatisticamente significante ao nível de 10\%; **estatisticamente significante ao nível de $5 \%$; ***estatisticamente significante ao nível de $1 \%$. Observação: o teste de normalidade não rejeitou a hipótese nula de uma distribuição normal; o hettes (teste de homocedasticidade) não indicou a presença de heterocedasticidade; o teste VIF apresentou coeficiente menor que 10 para todas as variáveis e, assim, não foi identificada multicolinearidade.

Fonte: Elaboração dos autores (2015).

A Tabela 5 expõe os resultados da relação entre o Gl e a variável retorno. O GI teve coeficiente positivo e significativo para ambos os modelos, além de que os resultados sugerem que o ele tem influência positiva no aumento do valor das ações.

Tabela 5 - Relação entre retorno e o grau de intangibilidade por intensidade tecnológica

\begin{tabular}{c|c|c|c}
\hline $\begin{array}{c}\text { Variáveis } \\
\text { explicativas }\end{array}$ & $\begin{array}{c}\text { Amostra } \\
\text { completa }\end{array}$ & $\begin{array}{c}\text { Alta e } \\
\text { média-alta }\end{array}$ & $\begin{array}{c}\text { Baixa e } \\
\text { média-baixa }\end{array}$ \\
\hline \multirow{2}{*}{$\mathrm{Gl}$} & $\begin{array}{c}0,855^{* *} \\
(0,349)\end{array}$ & $\begin{array}{c}2,977^{* * *} \\
(0,692)\end{array}$ & $\begin{array}{c}0,239 * \\
(0,50)\end{array}$ \\
\hline \multirow{2}{*}{$\mathrm{LC}$} & $-1,363^{* * *}$ & $-0,035$ & $-1,111$ \\
& $(0,487)$ & $(0,779)$ & $(2,19)$ \\
\hline \multirow{2}{*}{ Leverage } & 0,003 & 0,025 & $-0,680$ \\
& $(0,052)$ & $(0,802)$ & $(0,136)$ \\
\hline \multirow{2}{*}{ IEO } & $-0,075$ & $-0,133$ & $-0,0913$ \\
& $(0,071)$ & $(0,080)$ & $(0,208)$ \\
\hline
\end{tabular}

(Continua)

\begin{tabular}{|c|c|c|c|}
\hline Size & $\begin{array}{c}-4,264 * * * \\
(0,727) \\
\end{array}$ & $\begin{array}{c}1,917 \\
(3,725) \\
\end{array}$ & $\begin{array}{c}-3,513^{* *} \\
(1,297)\end{array}$ \\
\hline Observações & 537 & 344 & 193 \\
\hline $\begin{array}{c}\text { Número de } \\
\text { grupos }\end{array}$ & 127 & 83 & 44 \\
\hline Rho & 0,041 & 0,370 & 0,410 \\
\hline $\begin{array}{l}\text { Teste de } \\
\text { Hausman }\end{array}$ & $7,44^{*}$ & $11,76^{* *}$ & 4,72 \\
\hline Efeitos fixos & SIM & SIM & NÃO \\
\hline $\begin{array}{c}\text { Teste de Breusch } \\
\text { e Pagan }\end{array}$ & $5,64 * * *$ & $8,89 * * *$ & 0,02 \\
\hline
\end{tabular}

Nota: *estatisticamente significante ao nível de 10\%; **estatisticamente significante ao nível de $5 \%$; ${ }^{* *}$ estatisticamente significante ao nível de 1\%. Observação: o teste de normalidade não rejeitou a hipótese nula de uma distribuição normal; o hettes (homocedasticidade) não indicou a presença de heterocedasticidade; o teste VIF apresentou coeficiente menor que 10 para todas as variáveis e, assim, não foi identificada multicolinearidade.

Fonte: Elaboração dos autores (2015).

Em relação às demais variáveis de controle, apenas size apresentou coeficiente associado negativo e significativo. Este resultado se assemelha aos modelos que utilizaram o ROE como variável dependente.

\section{CONSIDERAÇÕES FINAIS}

O objetivo desta pesquisa foi identificar a relação entre Gl e desempenho econômico-financeiro das indústrias brasileiras de acordo com sua intensidade tecnológica. Para tanto, foi levantada uma amostra com dados de 198 empresas listadas na BM\&FBovespa nos anos 2012, 2013 e 2014, por meio da base de dados Economática.

Diante de tais observações, a fim de responder se existe relação entre $\mathrm{Gl}$ e desempenho das organizações, seguiu-se uma análise estatística em painéis desbalanceados em três cenários: (1) para a amostra total de indústrias; (2) para indústrias de alta e média-alta intensidade tecnológica; e (3) para indústrias de baixa e média-baixa intensidade tecnológica.

As evidências encontradas por meio da análise dos dados em painel sugerem haver relação significativa entre Gl e desempenho econômico-financeiro 
para as variáveis explicativas ROE e "retorno". Entretanto, não foram encontradas diferenças significativas para as empresas de distintas intensidades tecnológicas.

Mais investigações, no entanto, são necessárias para a confirmação de tais resultados. Sugere-se, como estudos futuros, replicar a pesquisa em setores isolados, buscando respeitar integralmente suas características. Outros métodos de avaliação ou mensuração da dimensão intangível devem ser testados, a fim de verificar se os resultados permanecem os mesmos. Da mesma forma, sugere-se avaliar ainda outros métodos econométricos para análise dos dados, como o método dos momentos generalizados (GMM). Ampliar as variáveis de análise da performance das indústrias também pode ajudar a entender com mais detalhes a relação entre intangibilidade e desempenho.

\section{REFERÊNCIAS}

AHANGAR, R. G. The relationship between intellectual capital and financial performance: an empirical investigation in an Iranian company. African Journal of Business Management, Ebène, v. 5, n. 1, p. 88-95, 2011. Disponível em: <http://bit.ly/2uS2Onz>. Acesso em: 3 mar. 2015.

ANTUNES, M. T. P.; MARTINS, E. Capital intelectual: seu entendimento e seus impactos no desempenho de grandes empresas brasileiras. BASE: Revista de Administração e Contabilidade da Unisinos, São Leopoldo, v. 4, n. 1, p. 5-21, jan./abr. 2007.

ARRIGHETTI, A.; LANDINI, F.; LASAGNI, A. Intangible assets and firm heterogeneity: evidence from Italy. Research Policy, Amsterdam, v. 43, n. 1, p. 202-213, 2014.

AXTLE-ORTIZ, M. A. Perceiving the value of intangible assets in context. Journal of Business Research, Amsterdam, v. 66, n. 3, p. 417-424, 2013.

BARNEY, J. Firm resources and sustained competitive advantage. Journal of Management, Thousand Oaks, v. 17, n. 1, p. 99-120, 1991.

Gaining and sustaining competitive advantage. 4. ed. Upper Saddle River: Prentice Hall, 2010. 512 p.

BESANKO, D. et al. A economia da estratégia. 5. ed. São Paulo: Bookman, 2011. 608 p.
BOMFIM, P. R. C. M. et al. Utilização de análise multivariada na avaliação do desempenho econômicofinanceiro de curto prazo: uma aplicação no setor de distribuição de energia elétrica. Revista $A D M . M A D E$, Rio de Janeiro, v. 15, n. 1, p. 75-92, 2011.

BONTIS, N. Intellectual capital: an exploratory study that develops measures and models. Management Decision, Bingley, v. 36, n. 2, p. 63-76, 1998.

BONTIS, N.; KEOW, W. C. C.; RICHARDSON, S. Intellectual capital and business performance in Malaysian industries. Journal of Intellectual Capital, Bingley, v. 1, n. 1, p. 85-100, 2000.

CABRITA, M. R.; BONTIS, N. Intellectual capital and business performance in the Portuguese banking industry. International Journal of Technology Management, Geneva, v. 43, n. 1-3, p. 212-237, 2008.

CARVALHO, F. M.; KAYO, E. K.; MARTIN, D. M. L. Tangibilidade e intangibilidade na determinação do desempenho persistente de firmas brasileiras. Revista de Administração Contemporânea, Curitiba, v. 14, n. 5, p. 871-889, 2010. Disponível em: <http://bit.ly/2vdzgjv>. Acesso em: 15 out. 2014.

CHAGAS, J. V. et al. Capital intelectual: sua mensuração utilizando o método VAICTM em seguradoras do 


\section{REFERÊNCIAS}

mercado brasileiro. Ciências Sociais em Perspectiva, Cascavel, v. 9, n. 17, p. 115-134, 2010.

CHANG, W. S.; HSIEH, J. J. Intellectual capital and value creation: is innovation capital a missing link? International Journal of Business and Management, Ontario, v. 6, n. 2, p. 3-12, 2011.

CHEN, M.; CHENG, S.; HWANG, Y. An empirical investigation of the relationship between intellectual capital and firms' market value and financial performance. Journal of Intellectual Capital, Bingley, v. 6, n. 2, p. 159-176, 2005.

\section{COMITÊ DE PRONUNCIAMENTOS CONTÁBEIS.} Pronunciamento técnico CPC 04 (R1): ativo intangível. Brasília, DF, 2010. Disponível em: <http://bit.ly/2teZhxp>. Acesso em: 15 jul. 2015.

CRUZ, B. P. A.; FREITAS; A. A.; SHARLAND, E. M. R. Reputação como fonte de vantagem competitiva: uma análise exploratória para uma instituição de ensino superior. In: ENCONTRO NACIONAL DE GRADUAÇÃO EM ADMINISTRAÇÃO, 20., 2009. Joinville. Anais... Rio de Janeiro: Angrad, 2009.

DENICOLAI， S.; ZUCCHELLA， A.; STRANGE， R. Knowledge assets and firm international performance. International Business Review, Amsterdam, v. 23, n. 1, p. 55-62, 2014. Disponível em: <http://bit.ly/2ujE36T>. Acesso em: 17 out. 2014.

DRUCKER, P. F. The coming of the new organization. Harvard Business Review, Brighton, v. 66, n. 1, p. 45-54, 1988.

EDVINSSON, L.; MALONE, M. S. Intellectual capital: realizing your company's true value by finding its hidden brainpower. New York: Harper Business, 1997.

ELBANNAN, M. A. Do analysts follow emerging economy firms with higher intangible assets? Empirical evidence from Egypt. Advances in Accounting, Amsterdam, v. 29, n. 1, p. 50-59, 2013.

FAMÁ, R.; BARROS, L. A. B. C. Q de Tobin e seu uso em finanças: aspectos metodológicos e conceituais. Caderno de Pesquisas em Administração, São Paulo, v. 7, n. 4, p. 27-43, 2000. Disponível em: <http://bit. ly/2uSb332>. Acesso em: 28 out. 2010.

FIETZ, E. E. Z.; SCARPIN, J. E. Estudo do grau de intangibilidade por meio das demonstrações contábeis: uma análise das empresas S/A de capital aberto constantes do índice IBRX - Índice Brasil. In: CONGRESSO USP DE CONTROLADORIA E CONTABILIDADE, 8., 2008, São Paulo. Anais... São Paulo: Universidade de São Paulo, 2008.

FURTADO, A. T.; CARVALHO, R. Q. Padrões de intensidade tecnológica da indústria brasileira: um estudo comparativo com os países centrais. São Paulo em Perspectiva, São Paulo, v. 19, n. 1, p. 70-84, 2005.

GITMAN, L. J. Princípios de administração financeira. 12. ed. São Paulo: Pearson Education, 2010. 775 p.

GODFREY, P. C.; HILL, C. W. L. The problem of unobservables in strategic management research. Strategic Management Journal, Hoboken, v. 16, n. 7, p. 519-533, 1995.

GUJARATI, D. N.; PORTER, D. C. Modelos de regressão com dados em painel. In: GUJARATI, D. N. Econometria básica. 5. ed. Porto Alegre: AMGH, 2011. cap. 16, p. 587-613.

HENDRIKSEN, E. S. Accounting theory. Illinois: Richard D. Irwin, 1965.

HENDRIKSEN, E. S.; VAN BREDA, M. F. Teoria da contabilidade. São Paulo: Atlas, 1999.

KAMATH, G. B. Intellectual capital and corporate performance in Indian pharmaceutical industry. Journal of Intellectual Capital, Bingley, v. 9, n. 4, p. 684-704, 2008. 


\section{REFERÊNCIAS}

KAPLAN, R. S.; NORTON, D. P. A estratégia em ação: balanced scorecard. Rio de Janeiro: Campus, 1997.

KAYO, E. K. A estrutura de capital e o risco das empresas tangível e intangível-intensivas: uma contribuição ao estudo da valoração de empresas. 2002. $126 \mathrm{f}$. Tese (Doutorado em Administração) - Faculdade de Economia, Administração e Contabilidade, Universidade de São Paulo, São Paulo, 2002.

KREUZBERG, F.; RIGO, V. P.; KLANN, R. C. Relação entre os indicadores de desempenho financeiro e a intangibilidade dos ativos: um estudo das empresas listadas na BM\&FBOVESPA. In: SIMPÓSIO DE ADMINISTRAÇÃO DA PRODUÇÃO, LOGÍSTICAE OPERAÇÕESINTERNACIONAIS, 17., 2013, São Paulo. Anais... São Paulo: Fundação Getulio Vargas, 2013. p. 1-15.

LAURETTI, C. M. A relação entre intangibilidade, desempenho financeiro e desempenho de mercado. 2011. 134 f. Tese (Doutorado em Administração de Empresas) - Centro de Ciências Sociais e Aplicadas, Universidade Presbiteriana Mackenzie, São Paulo, 2011.

LEV, B. Intangibles: management, measurement, and reporting. Washington, DC: Brookings, 2001.

MATARAZZO, D. C. Análise financeira de balanços: abordagem gerencial. 7. ed. São Paulo: Atlas, 2010. 372 p.

MAZZIONI, S. et al. A relação entre a intangibilidade e o desempenho econômico: estudo com empresas de capital aberto do Brasil, Rússia, Índia, China e África do Sul (Brics). Advances in Scientific and Applied Accounting, São Paulo, v. 7, n. 1, p. 122-148, 2014.

MONOBE, M. Contribuição à mensuração e contabilização do goodwill não adquirido. 1986. 183 f. Tese (Doutorado em Contabilidade) - Faculdade de Economia, Administração e Contabilidade, Universidade de São Paulo, São Paulo, 1986.
MOURITSEN, J. Driving growth: economic value added versus intellectual capital. Management Accounting Research, Amsterdam, v. 8, n. 6, p. 15-23, 1988.

NASCIMENTO, E. M. et al. Ativos intangíveis: análise do impacto do grau de intangibilidade nos indicadores de desempenho empresarial. Reflexão Contábil, Maringá, v. 31, n. 1, p. 37-52, 2012.

PEREZ, M, M.; FAMÁ, R. Ativos intangíveis e o desempenho empresarial. Revista Contabilidade e Finanças, São Paulo, v. 17, n. 40, p. 7-24, 2006. Disponível em: <http://bit. ly/2sRrzPc>. Acesso em: 20 ago. 2014.

PETERAF, M. A. The cornerstones of competitive advantage: a resource-based view. Strategic Management Journal, Hoboken, v. 14, n. 3, p. 179-191, 1993

PULIĆ, A. The principles of intellectual capital efficiency: a brief description. Zagreb: Croatian Intellectual Capital Center, 2008. Disponível em: <http://bit.ly/2t4KIS2>. Acesso em: 4 jan. 2015.

REILLY, R. F.; SCHWEIHS, R. P. Valuing intangible assets. New York: McGraw-Hill, 1998. 518 p.

REZAIE, H.; SALEHI, H. Investigating the relationship between intangible assets and heterogeneous firms listed in Tehran Stock Exchange. European Online Journal of Natural and Social Sciences, Praha, v. 4, n. 1, p. 960-969, 2015. (Edição especial).

RIAHI-BELKAOUI, A. Intellectual capital and firm performance of US multinational firms: a study of the resource-based and stakeholder views. Journal of Intellectual Capital, Bingley, v. 4, n. 2, p. 215-226, 2003.

SABOLOVIC, M. Business performance analysis via VAICTM. European Research Studies, Piraeus, v. 12, n. 3, p. 77-82, 2009. 


\section{REFERÊNCIAS}

STEWART, T. A. Intellectual capital. New York: Currency Doubleday, 1997. Intellectual capital: the new wealth of organizations. New York: Doubleday, 1999.

SVEIBY, K. E. A nova riqueza das organizações: gerenciando e avaliando patrimônios. Rio de Janeiro: Campus: 1998.

Methods for measuring intangible assets. Helsinki: SKA Global Oy, 2010. Disponível em: <http:// bit.ly/2sR6Smr>. Acesso em: 25 jul. 2015.

TAN, H. P.; PLOWMAN, D.; HANCOCK, P. Intellectual capital and financial returns of companies. Journal of Intellectual Capital, Bingley, v. 8, n. 1, p. 76-95, 2007.
TROMBETA, M. S. Grau de intangibilidade e o desempenho econômico das empresas no mercado acionário brasileiro. 2010. 50 f. Trabalho de Conclusão de Curso (Especialização) - Universidade Federal do Rio Grande do Sul, Porto Alegre, 2010.

WERNERFELT, B. A resource-based view of the firm. Strategic Management Journal, Hoboken, v. 5, n. 2, p. 171-180, 1984.

WOOLDRIDGE, J. M. Correlated random effects models with unbalanced panels. Michigan: Michigan State University, 2010. mimeo.

YU, K. L. et al. An empirical study of the impact of intellectual capital on business performance. Journal of Information \& Knowledge Management, New Jersey, v. 10, n. 1, Mar. 2011. 